\title{
The Vitebsk Project by Kazimir Malevich: A Case-Study of Urban Life Modernization
}

\author{
Yulia Alexandrovna Griber ${ }^{1}$ \\ Aleksandr Grigorevich Egorov² \\ 1,2Smolensk State University, Smolensk, Russian Federation \\ 1Email:Y.Griber@gmail.com
}

Doi:10.5901/mjss.2015.v6n4s4p309

\section{Abstract}

\begin{abstract}
The article is given over to analyzing the urban life modernization project implemented by Kazimir Malevich in Vitebsk in 19191920. The background of the project, its format and participants are described. The theoretical justification for the case study selection as a main research method is provided, and stages, a selection of research units and results verification methods are described. As research materials the urban life modernization projects developed by Malevich for its various spheres, such as: stage architecture, household articles, residential buildings and urban functions, were taken. The key structural features of the urban space modernization model proposed by Malevich are presented. Their analysis, in the context of social and cultural environment, was carried out and the following key substantive characteristics were defined: The idea of a new world building, the idea of unity and the idea of movement and development. The ideological proximity of the project to the social and political utopias and visionary architecture is shown. The development of Vitebsk project principles in the urban space of the following years and their use possibility under modern conditions is considered.
\end{abstract}

Keywords: Kazimir Malevich, modernization, case-study, urban life, project.

\section{Introduction}

Kazimir Malevich is well known worldwide as an extraordinary artist. At the same time, his projects did not withdraw into a two-dimensional canvas plane. His artistic ideas were much more large-scale and ambitious. He considered Suprematism as a promising modernization project, understanding the process extremely broadly - in the "planetary" and even "space", "universal" scale.

Despite worldwide steady interest into the artist's works and a great number of insightful and deep research into his work, which are presented in the books by Douglas (1980, 1994), Han-Magomedov (2009), Marcadé (1990), Shatskikh $(1993,1996,2001)$ and Zhadova (1982), it must be acknowledged that his ideas in the sphere of urban design and urban life modernization are still poorly studied. Primarily researchers are attracted by the picturesqueness of Malevich's Suprematism, his rich artistic biography and bright philosophy. The bare fact that the artist proved himself as a progressive and prominent theorist of everyday life modernization and that his ideas can be used effectively in modern social practices, remains outside general research interest. Analysis of that particular promising aspect is represented in the article.

\subsection{Background of the Project}

The starting point for the formation of the everyday life modernization concept of Kazimir Malevich was the awareness of chaos and the lack of order in the existing space around it. This sense is, in principle, natural and widespread during the years of social upheavals, when the established world picture is destroyed and a new one is just forming; which is very important for the birth of new mythology.

The artist clearly felt that urban life is crowded with "ghosts" of the past. By using metaphors and images of death he painted a horrible picture, representing what he saw around. For him, the urban space consisted of "dead" buildings, whose "bodies" broke down due to rapid society development. The buildings "died", because their "dresses could not hold the modern race". Now, the concrete walls "cover the senile bodies of the dead" (Malevich 2001, pp. 61-62). All around are the "absolutely beautiful skeletons that have lost their image and by which you can't no longer know both the facial expressions and thoughts" (Malevich 2001, pp. 365-366).

In such a situation K. Malevich suggested that one must act decisively: "to bury" (Malevich 2001, p. 60) the dead 
and look for new ways of expressing the rapid time passage. The artist was passionate about a new artistic idea formation, an active and creative search for a new means of expressing the social meanings needed to create a perfectly organized place, where a person lives, both in the social and cultural plan. At the same time, he knew very well that urban life consists of the history "wreckage", which cannot be gotten rid of. It is impossible to evacuate people, to destroy all that is already hopelessly out of date and to build new cities for the new society. Society can't simply turn over "a new leaf" and is forced "to edit" the accumulated objects every time, by remaking, adjusting and upgrading urban life to its changed requirements. So, he decided to create a draft, a new edition of a city.

\subsection{Experiment format}

The role of laboratory such as it was, which provided a convenient place to work off the ideas that shall be continually implemented in the urban space of the whole country and even the whole world in the future was played by Vitebsk - a small town in the west of the Russian Soviet Federative Socialist Republic (RSFSR), where the artist came in October 1919 to head a workshop at the People's Art School of "a new revolutionary sample", which was headed by Marc Chagall.

Here for the first time the artist had the really unique opportunity to put his ideas into practice and indeed affect the urban culture and create a new urban environment. Trying to "dress the technical ... tripe into the highest form of art spirit" (Malevich, 1989), K. Malevich developed a plan of city modernization and submitted his project by participating in the reconstruction of buildings and infrastructure in Vitebsk in 1919-1920.

\subsection{Project team}

The creation of a modern urban environment filled with Suprematist ornaments was an extremely large scale project, and it was hard for the artist to cope with it alone. Truly speaking, he did not aspire to that. An important principle of the Vitebsk experiment of Kazimir Malevich was the idea of collective creativity (national unity). From the very beginning the project was collective and implemented by the forces of "the UNOVIS" group ("The Champions of the New Art"), which was formed in early 1920, by a team of students and teachers from the People's Art School in Vitebsk and which played a major role in the development of the urban space modernization concept proposed by Malevich. Talented young artists, such as El Lissitzky, I. Chashnik, N. Suetin, L. Yudin, L. Khidekel, V. Ermolaeva, and N. Kogan were among the active members of UNOVIS.

\section{Research Method}

\subsection{Case study selection justification}

Research into the modernization project suggested by Malevich was carried out with the case study method and developed relying on the works of George (1979), Hartley (1994), Pettigrew (1990), Schramm (1971), Stake (1995), and Yin $(1993,2009)$.

The essence of the case-method used in various fields of science lies in the fact that this type of empirical research is aimed at the deep study of features and complexity of the particular case related to a certain phenomena class. It gives an idea about the decision or set of decisions, describes why those decisions were taken, how they were implemented and led to what result.

In order to analyze Malevich's Vitebsk project, the selection of the case study method was based on the recommendations of Yin (2009) and justified by the fact that in this case it was impossible to accurately determine the boundaries between an event and related social factors along with a large number of variables and a large number of information sources.

\subsection{Data collection procedures}

The study procedure included 2 distinct stages.

During the first stage, the strategy was descriptive and involved finding the answers to the question of "How?". The main objective was a detailed description of Malevich's Vitebsk project as an independent social phenomenon.

During the second stage, we used the explanatory (analytical) approach to find an answer to the question of "why?" and explain the causes and factors which influenced the situation. 
The case study method employed multiple levels of analysis (single object level vs. urban level) and multiple types of data collection (archives, observations).

\subsection{Unit selection and research material}

The research units selection was guided by George (1979) and Pettigrew's (1990) recommendations.

The research materials were taken from the modernization projects developed by Malevich for the different spheres of urban life:

Stage architecture: Sketches of costumes, curtains and decorations, the development of stage lighting for the futuristic opera "Victory over the Sun" and "Suprematist ballet";

Household articles: Book design, design sketches for porcelain, toys, furniture and clothes, ornament patterns for textiles, Suprematist stitch embroidery and the application developed for the decoration of ribbons, tapestries, towels, tablecloths, scarves, pillow covers, dressing gowns, bags, fans, and screens;

Residential buildings: Arkhitektons, Suprematist panels covering the building facades, murals designs;

Urban functions: Signboards and service company designs, trams sketches, designs for railway wagons, celebratory decorations for the individual elements of the urban environment (paintings for orator's platforms, banners and billboards).

In the study we have used visual documents from the holdings of the Russian Museum, the Hermitage (St. Petersburg, Russia) and the State Archive of the Vitebsk Region (Vitebsk, Belarus). Further to this the published theoretical works and epistolary heritage of Kazimir Malevich were analyzed (1918, 1989, 2000, 2001).

More than one unit of analysis in each case was considered as a way to respond to researchers' biases (Yin 1993). This implied that, in addition to developing contrasts between the cases, the research was focused on contrasts within the cases (Hartley 1994).

\subsection{Results verification}

The research results were directly and indirectly verified by direct observation and logical coordination with other previous directly checked judgments.

\section{Results}

Following the logic of research, it was during the first stage that a detailed project material description was drawn up and the key structural features were allocated. During the second stage their analysis, in the context of social and cultural environment, was carried out and the key substantive characteristics were defined.

\subsection{Description}

"It's a weird provincial town.

Like many cities in the Western Region - it is made of a red brick. Sooty and dull. But this town is especially weird. Here the main streets are covered with white paint over the red brick. And on a white background green circles are scattered. Orange squares. Blue rectangles.

That is Vitebsk in 1920. The brush of Kazimir Malevich has touched its brick walls. "The squares are our palettes" sounds from those walls...

Before ones eyes there are orange circles, red squares, green trapezes...

Suprematist confetti is scattered in the streets of this dumbfounded town..." - such was the impression that 1920s Vitebsk left on the famous Soviet director S. Eisenstein, who arrived in the town after Malevich's project was implemented (1963, pp. 279-280).

The environment created in Vitebsk represented a single Suprematist work, consisting of Suprematist signboards, paintings of celebratory platforms, Suprematist ornaments, fabrics, banners and giant Suprematist panels, which cover the building facades. Despite the different sizes, shapes, spheres of use and social functions, all the objects that implement the principles of urban environment modernization were represented by a single text, which was characterized by an amazing stylistic commonality and represented a complete and independent cultural phenomenon.

The structure of all the urban life modernization projects was based on the equal principles of background and picture organization. 


\subsubsection{White background}

All of Malevich's projects are characterized by a uniform, all-binding white background. "An empty" white space combines the decorative fabrics, posters, paintings, utensils decoration, and objects of decorative and applied arts.

At the same time, in the structure of images there was no conditional border, or frame, which is normally used as a way of meaning "compression". For example, in the town space, the buildings structure, under which a picture painted on the facade "adapts", acts usually as a structure, which represents a hidden visual foundation and traditionally organizes and contracts a composition. This doesn't happen with K. Malevich. The artist breaks not only that rule, but also, in general, the idea that objects have borders. He binds all their pieces together with a single white color.

\subsubsection{Painting}

On a white background the artist places "two-dimensional" geometric shapes. In this case the painting is created by using the linear contour, which serves as a visual border and divides the external (background) and inner space (shapes).

The contour shapes are used as the abstract formulas and together they constitute a kind of "palette" (a similar version of the alphabet was used later in the Bauhaus, by T. van Dusburg, P. Mondrian and other artists). A set of Malevich's geometric shapes includes a square, a cross, a sign of cross-placed black and white squares (elements of a "chessboard"), a circle and a number of others. The shapes are unequal in terms of their importance. They form a certain hierarchy, on top of which there is a square as a form.

The Suprematism geometric shapes together make a universal dictionary of forms with ample opportunities to combine them and adjust the composition construction. Without exception, all the paintings created by the artist for the urban space represent the combinations of several geometric shapes and thereby they are different from Suprematist paintings, where, in addition to multi-figured compositions, there are also the images of single geometric marks.

\subsection{Analysis}

\subsubsection{The Idea of a new world building}

Malevich was building his urban space modernization project based on the total repainting of all city facilities. In the repainting K. Malevich saw the creation anew. For him, "to paint" is almost identical in meaning to "to deify" or "to consecrate". "To make art is almost the same as to deify, to paint, and to consecrate. That is why the citizen strives to consecrate his home and paint, make his building artistic, so that it becomes, moves, into the top category, and, if possible, seeks to its inner, artistic category" (Malevich 2001, p. 323), - his heartfelt belief.

The idea of building a new world was in good agreement with the theosophical component of Suprematism. A strategy of urban space reorganization proposed by K. Malevich was based on the fact that both town planning art and Suprematism were seen by the artist as a promising project for rationalistic world order, a world transformation based on the ideals of universal harmony, as the Creation. "Mystery is the mark of creation, and the mark is the real view of mystery, where one perceives the sacraments of the New" (Malevich 1918, p. 34), - K. Malevich writes.

For the artist the uniform background became a distinctive technique of matter dissolution, which allowed them to consider all the existing buildings as a kind of "seed-bed", on which you can grow a new painting. K. Malevich first used such a metaphor in 1919, when he wrote about the beginning of object "dissolution" in the works of C. Monet. The artist figuratively proved that, already in Impressionism, the thing presented in the painting is just a "seed-bed", which exists only in order "to grow the painting". "We are talking about how beautiful the rye and how good the meadow grasses, but are not talking about the ground. This way the picturesque should be considered, but not a samovar, a cathedral, a pumpkin, or La Gioconda. And when the artist writes, implants the painting and the subject serves as a seed-bed to him, he shall sow the painting so that the subject can get lost, because the painting visible to the painter will grow out of it. But if instead of painting a cleaned bash, a pumpkin, a pot, a pear, or a jug gleaming, then there will be a bed, on which nothing has risen" (Malevich 2001, pp. 133-134).

\subsubsection{The Idea of unity}

The white color acted as the role of background and by no accident became one of the main symbols of modernization in the Vitebsk project. For Malevich, it had clear and unambiguous semantics, its basic meanings were "pointlessness" (Malevich 2001, p. 211), "renewal", "purity" (Malevich 2001, p. 80), "order", "classical economics" and "high geometrism 
of consciousness" (Malevich 2000, p. 244). Malevich "predicted" that in the future all forms of urban culture "will be without any color", "an even greater center painted in white will occur" and that "The future will consist solely of white" (Malevich 2000, pp. 179-180).

On the one hand, the white background helped the artist to express his "non-figurative senses" and convey his strong sense of "world" space. On the other hand, and most importantly, in the white city the idea of unity resounded for K. Malevich - "the all-color unity that is unlike any color, but it creates the picturesque integral all-color beginning", through which you can well express something that, according to the artist, socialism "dreamed": "the idea of achievement, the international and fusion of all nations into one indissoluble node" (Malevich 2000, p. 154). This new image was well suited to the construction of space and the proletarian unity of people. In the new urban space there are no boundaries. And the only identity that had to be formed and maintained was self-awareness as the "Earth Owellers (People)" (Almanac of Unovis 2003, Sh. 10).

The main idea of the Vitebsk modernization project was to create a new environment in the urban space. It was to become comprehensive and fill in all aspects of human life. Despite the different types of objects that were involved in the modernization project, at each occurrence their transformations were subordinated to the uniform principles. In this way the whole city was immersed in a kind of "solution" with special properties, similar in all spatial parts. Malevich, who was convinced of the impossibility to change the existing architecture, has used this principle to set the new over the old. And the new, modern society life was to be built in that modernized environment.

\subsubsection{The Idea of movement and development}

In order to create a feeling of constant movement, a complex, multi-layered and multi-figured composition was used in the Vitebsk project. The combinations of geometrical figures showed "the world is under construction". Moreover it was the world, the reorganization of which is taking place right now, at this moment, right in the presence of the spectator.

To convey a sense of dynamism, movement and development, the artist actively uses the placement technique of "figure behind figure" by placing the simple geometric shapes on a white wall plane so that one figure looks out from the other, so the figures partially overlap each other, the shapes coming into contact with the edges and "dive" under each other.

For example, in the painting of Vitebsk trams, where the images are built of simple geometric shapes so that their position creates the effect of not only tram movement, but also the whole working movement, or in the composite structure of wall painting projects made by Malevich, where the feeling of movement and the dynamic perception of lines is based on the broken structure axis.

Using color planes, he strives to express "the current of motion itself, like if you touch an electrical wire", to show the connection between the moving man and the space, which, together with the synthesized influence of art and architecture in the urban environment, gave a new sense: namely, the sense of dynamics, velocity and time.

\section{Discussion and Conclusions}

It should be noted that such ideas about the existence of rational structures capable of turning chaos into space and arranging the existing reality via a verified harmony have a long and rich history in religion, literature, philosophy and art, and underlie most of the known social and political utopias and visionary architecture projects. Even the theorists, who developed solely social utopias, for example, C. Fourier (1841) or F. Buonarroti (1909), somehow inevitably described how they imagine the urban space of their ideal worlds.

At the same time, the avant-gardes and utopian-revolutionaries are united by their enthusiastic, passionate attitude towards the project of an ideal future and an aversion to the past, to the real past in life and art. In either case we can see the attempt to create something new, united and understandable to everyone through the language of the future. The same approach is also characteristic of $\mathrm{K}$. Malevich's concept.

But unlike the majority of his contemporary architects and artists, K. Malevich intended to implement, in practice, his artistic ideas to transform the urban spaces and did it successfully enough.

At that time, many ideas of $\mathrm{K}$. Malevich related to urban everyday life modernization seemed and in practice proved to be rather utopian. However, in the space of Vitebsk it was convincingly demonstrated that his approach really allows you to optically transform the world in a rather short period of time.

A special look at the objects of urban life became a new kind of way to "revive" the dead urban matter for K. Malevich. In his opinion, all of them were a single textured mass, from which it was possible to make new forms, optically destroying their tectonics and making the decor unrelated to their structure in anyway. He considered the whole urban 
fabric as a single environment, or as a blank canvas, which you can use for expressing new artistic ideas and creating a modern urban environment.

The urban life modernization model introduced by Malevich had great potential and was extremely productive. The Vitebsk space modernization project suggested by Malevich, as was remarked on by Khan-Magomedov, had played the role of "the peculiar crystals thrown into the supersaturated solution" (Khan-Magomedov 1996, p. 104). His influence is clearly seen not only in the works of Malevich's students (I. Chashnik, N. Suetin, El Lissitzky, L. Khidekel) and many Soviet architects (N. Ladovsky, I. Leonidov, K. Melnikov, M. Ginsburg, A. Nikolsky, I. Golosov, L. Rudnev, I. Fomin and others), but also in the creative searches of the Dutch group "De Stijl", and the artistic principles of the German Bauhaus.

After leaving a distinctive mark in the history of art, forming the basis of a number of architectural and urban ideas, the bright urban life modernization project of $\mathrm{K}$. Malevich continues its socio-cultural transformations in the urban culture of contemporary society. The ideas of $\mathrm{K}$. Malevich are well suited to modern practice, because they have the characteristics that bring them closer to the media through the impact method. They are recognizable, lend themselves well to the decomposition into elements, and, after being "chewed" by modern urban design, still keep their status of a powerful resource for urban life modernization and the gentrification of urban territories.

\section{Acknowledgments}

The research is executed within the base part of the state task of the Russian Ministry of Education and Science (task No. 2014/381 to perform public works in the sphere of scientific activity).

\section{References}

Buonarroti, F. (1909). Babeuf und die Verschwörung für die Gleichheit mit dem durch sie veranlassten Prozess und den Belegstücken. Stuttgart: Dietz.

Douglas, Ch. (1980). Swans of Other Worlds: Kazimir Malevich and the Origins of Abstraction in Russia. Ann Arbor: University of Michigan Press.

Douglas, Ch. (1994). Kazimir Malevich. London: Thames and Hudson Ltd.

Fourier, Ch. (1841). Oeuvres completes. Bd. 4. Théorie l'unité universelle. Paris: Librairie Sociétaire.

George, A. L. (1979). Case studies and theory development: The method of structured, focused comparison. In P. G. Lauren (Ed.), Diplomacy: New approaches in history, theory, and policy (pp. 43-68). New York: Free Press.

Hartley, J. F. (1994). Case studies in organizational research. In C. Cassell and G. Symon (Eds.), Qualitative methods in organizational research: A practical guide (pp. 209-229). London: Sage.

Marcadé, J.-Cl. (1990). Malévitch. Paris: Nouvelles Editions francaises.

Pettigrew, A. M. (1990). Longitudinal field research on change: Theory and practice. Organization Science, 1 (3), 267-292.

Schramm, W. (1971). Notes on case studies of instructional media projects. Working paper for the Academy of Educational Development. Washington D.C.

Stake, R. E. (1995). The art of case study research. London: Sage.

Yin, R. K. (1993). Applications of case study research. Applied Social Research Series, Vol. 34. London: Sage.

Yin, R.K. (2009). Case Study Research: Design and Methods (4th ed.). Los Angeles: Sage.

Zhadova L. (1982). Malevich. Suprematism and Revolution in Russian Art 1910-1930. London: Thames and Hudson.

Almanac of Unovis No.1: facsimile edition (2003). Prep. of text, publ., ent. art. by T. Goryacheva. M.: SkanRus.

Arskaya, I. et al. (2000). Kazimir Malevich in the Russian Museum. SPb.: Palace Editions.

Malevich, K. (1918). On Poetry (pp. 33 - 34). Art, No.1.

Malevich, K. (1989). Manuscript "A note on architecture". Kazimir Malevich. 1878-1935: an exhibition catalog (pp. 112 - 124). Moscow, Leningrad, Amsterdam.

Malevich, K. (2001). Black square. Enter. art. and comments by A.S. Shatskikh. SPb.: Azbuka.

Sarabyanov, D., Shatskikh, A. (1993). Kazimir Malevich: Painting. Theory. M.: Art.

Khan-Magomedov, S.O. (2009). Kazimir Malevich. M.: Foundation "Russian avant-garde".

Khan-Magomedov, S.O. (1996). Architecture of the Soviet avant-garde. In 2 books Book. I: Problems of form making. Masters and movements. M.: Stroyizdat.

Shatskikh, A.S. (1996). Kazimir Malevich. M.: SLOVO.

Shatskikh, A.S. (2000). Malevich K. Collected Works. In 5 vol. Vol. 3. Suprematism. The world as pointlessness or eternal rest. With the application of letters from K.S. Malevich to M.O. Gershenzon (1918-1924). M.: Gilea.

Shatskikh, A. (2001). Vitebsk. The life of art 1917-1922. M.: Languages of Russian Culture.

Eisenstein, S.M. (1963). Notes on V.V. Mayakovsky. V.V. Mayakovsky in the memoirs of contemporaries (pp. 279 - 280). Notes of N.V. Reformatorskaya; enter. Art. by Z.S. Paperny. M.: State publ. house of artist. lit. 